\title{
Diarrhea and Hypokalemic Rhabdomyolysis Due to Apoptotic Colitis as the Initial Manifestation of Common-Variable Immunodeficiency in an Adolescent
}

\author{
David Green', Nina Dave², Hua Liu33, Charu Subramony4, Michael J. Nowicki ${ }^{3}$ \\ ${ }^{1}$ School of Medicine, University of Mississippi Medical Center, Jackson, USA \\ ${ }^{2}$ Division of Pediatric Allergy-Immunology, University of Mississippi Medical Center, Jackson, USA \\ ${ }^{3}$ Division of Pediatric Gastroenterology, University of Mississippi Medical Center, Jackson, USA \\ ${ }^{4}$ Department of Pathology, University of Mississippi Medical Center, Jackson, USA \\ Email: $\underline{\text { mnowicki@umc.edu }}$
}

Received 8 March 2014; revised 5 April 2014; accepted 12 April 2014

Copyright (C) 2014 by authors and Scientific Research Publishing Inc.

This work is licensed under the Creative Commons Attribution International License (CC BY). http://creativecommons.org/licenses/by/4.0/

(c) (i) Open Access

\begin{abstract}
We present the case of an adolescent who presented with rhabdomyolysis due to severe hypokalemia arising from chronic diarrhea. Initial evaluation for celiac disease, known to present in this manner, was negative. Further evaluation with colonoscopy showed a normal appearing colon but biopsies showed a significant number of apoptotic cells in the mucosal crypts supporting a diagnosis of apoptotic colitis. Investigation into the cause of apoptotic colitis resulted in a diagnosis of common variable immune deficiency due to a defect in the inducible T-cell costimulator (ICOS) gene. Physicians should be aware of this uncommon condition and the importance of mucosal biopsy despite the presence of normal appearing mucosa.
\end{abstract}

\section{Keywords}

Apoptotic Colitis, Common-Variable Immune Deficiency, Hypokalemia, Rhabdomyolysis

\section{Introduction}

The patient described herein exemplifies the complex manner in which immunodeficiency states can present, pointing out the need for persistence and diligence in order to secure the correct diagnosis. Initial presentation of hypokalemia-induced rhabdomyolysis in an adolescent with chronic diarrhea, stunted growth, and weight loss 
prompted evaluation for an intestinal cause of the findings, in particular celiac disease. When the initial evaluation failed to secure a diagnosis, further investigation employing colonoscopy discovered the rare finding of apoptotic colitis. Causes of apoptotic colitis are few, providing a narrowed differential diagnosis from which the final diagnosis of CVID was made. Below is a detailed description of the evaluation of the patient, presented to point out the interplay of the various uncommon clinical features and laboratory findings seen in this case. Also, we offer a review of apoptotic colitis, a rare finding in children. Finally, a brief review of the diagnosis of CVID is presented.

\section{Case Report}

A 14-year-old white male presented to his local emergency department with fatigue, diffuse muscle pain, and severe weakness. The patient reported a life-long history of diarrhea, typically occurring twice per day, described as loose to watery in consistency, without blood or mucus. He denied abdominal pain, anal pain, nausea, vomiting, and nocturnal stooling. He reported a long history of poor growth, exacerbated by a recent ten pound weight loss. Past medical history was significant for repeated skin infections requiring oral antibiotics and incision and drainage; pneumonia twice; sinus infections (2 - 3/year); and recurrent otitis media as an infant requiring placement of pressure equalizer tubes. Family history was positive for peptic disease and negative for celiac disease, inflammatory bowel disease, and malabsorption disorders. Examination showed a weight of $38.7 \mathrm{~kg}(<$ $5^{\text {th }} \%$ ile), height of $156 \mathrm{~cm}\left(10^{\text {th }} \%\right.$ ile $)$, and body mass index of $15.9 \mathrm{~kg} / \mathrm{M}^{2}\left(<5^{\text {th }} \%\right.$ ile). There was no scleral icterus. His heart and lung examinations were normal. His abdomen was soft, non-tender, without hepatosplenomegaly or masses. He had a diffuse psoriatic rash involving his scalp, trunk, and extremities. Mild digital clubbing was noted. Perianal examination showed no fissures, fistulae, or skin tags. Rectal examination showed normal position and tone with liquid, occult-blood negative stool in the vault. Laboratory evaluation was significant for severe hypokalemia $\left(\mathrm{K}^{+}=1.9 \mathrm{mmol} / \mathrm{L}, \mathrm{nl}=3.5\right.$ - 5.2) necessitating hospitalization for correction with intravenous fluids and potassium administration. Upon discharge from the hospital he was referred to gastroenterology for concerns of celiac disease due to poor nutrition, long-standing diarrhea, and hypokalemia.

The patient was seen in clinic where serum immunoglobulin (Ig) A and anti-tissue transglutaminase (TTG) IgA were obtained. The TTG-IgA was normal $(<4 \mathrm{U} / \mathrm{L})$, however, the serum IgA was low $(17 \mathrm{mg} / \mathrm{dl}$, normal = 70 - 400) making the results of the TGG-IgA unreliable. He returned for diagnostic esophagogastrodoudenoscopy (EGD) one week later, at which time he was again experiencing fatigue, weakness, and muscle pain. Laboratory evaluation showed hypolkalemia $(1.6 \mathrm{mmol} / \mathrm{L}, \mathrm{nl}=3.5-5.1)$, hypocalcemia $(6.9 \mathrm{mg} / \mathrm{dl}, \mathrm{nl}=9.4-10.2)$, mild transaminitis (alanine aminotransferase $(\mathrm{ALT})=63 \mathrm{U} / \mathrm{L}, \mathrm{nl}=0-40$; aspartate aminotransferase level (AST) $=46 \mathrm{U} / \mathrm{L}, \mathrm{nl}=0$ - 39), elevated creatinine kinase (1979 U/L, $\mathrm{nl}=38$ - 174), normal albumin ( $4.4 \mathrm{~g} / \mathrm{dl}, \mathrm{nl}=3.5$ 5.1), and normal magnesium $(1.6 \mathrm{mEq} / \mathrm{l}, \mathrm{nl}=1.3-2.0)$. EGD showed chronic gastritis and mild duodenitis, but no histological evidence for celiac disease. He was admitted for treatment of the electrolyte disorder. As the electrolytes corrected the serum creatinine kinase also normalized and he experienced improvement in his all symptoms, except for diarrhea. Colonoscopy was performed to evaluate for colitis as an etiology of the persistent diarrhea. The colonic mucosa was visually normal in appearance (Figure 1). Biopsies revealed no inflammation or crypt distortion, but did show an increased number of apoptotic cells within the mucosal crypts

(Figure 2) from the transverse colon to the rectum, consistent with a diagnosis of apoptotic colitis.

The differential diagnosis for apoptotic colitis is limited, including drug-related colonopathy, graft-versushost disease (GVHD), and immunodeficiency disorders, including human immunodeficiency virus (HIV) infection. The patient had a past history of recurrent infections and was shown to have low IgA levels as part of the initial evaluation for celiac disease, so an immunodeficiency evaluation was initiated. The findings of the immune work up are found in Table 1. The patient was diagnosed with common variable immunodeficiency (CVID). Genetic testing was done for the common underlying defects including transmembrane activator, calcium-modulator, and cycophilin ligand interactor (TACI), B-cell activating factor receptor (BAFF-R), and inducible T-cell costimulatory (ICOS); he was found to have ICOS deficiency. Treatment was initiated with monthly immunoglobulin replacement (Gamunex $\left.{ }^{\circledR} 10 \%\right)$.

He continued to have ongoing intermittent bouts of weakness due to hypokalemia despite oral replacement therapy prompting evaluation for other potential causes. Evaluation for renal loss of electrolytes was normal. Hypokalemia periodic paralysis was ruled out by normal sequencing of the commonly involved genes (CACNL1A3 gene and SCN4A gene). 

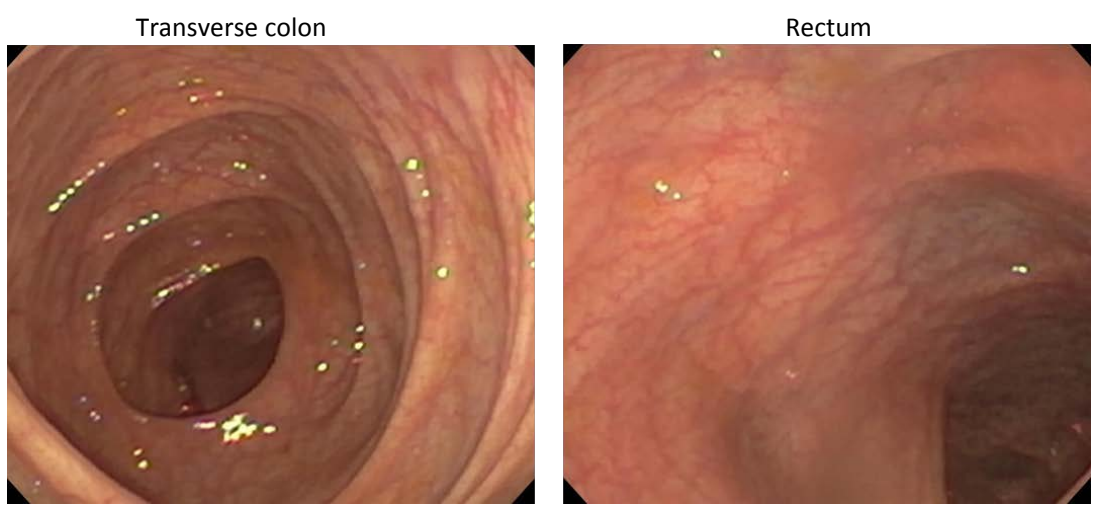

Figure 1. Endoscopic findings. The colonic mucosa appeared normal throughout as shown in photographs from the transverse colon and rectum.
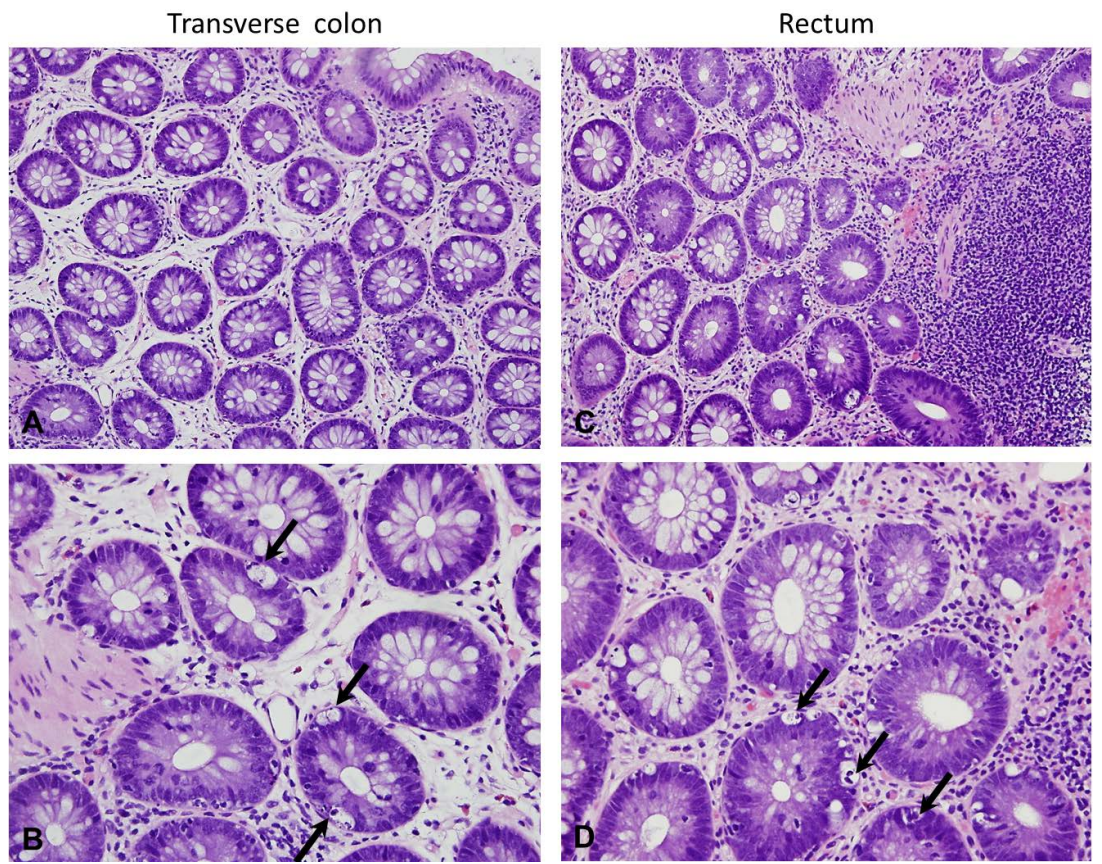

Figure 2. Histological findings. Biopsies from the transverse colon (A and B) and the rectum $(C$ and $\mathrm{D})$ revealed no inflammation or crypt distortion. An increased number of apoptotic cells were seen within the mucosal crypts (B and D; arrows) consistent with a diagnosis of apoptotic colitis (A and B, 20× magnification; C and D, 40× magnification).

Repeat colonoscopy was performed 9 months after initiation of immunoglobulin therapy again revealed normal appearing mucosa but persistence of apoptosis. He continued to have loose stools and intermittent bouts of hypokalemia, but both had improved significantly. The patient also had marked improvement in his psoriatic skin lesions.

\section{Discussion}

At initial presentation to our institution, the patient was noted to have severe hypokalemia and rhabdomyolysis. Rhabdomyolysis may result from a wide variety of causes, including primary muscle disease (metabolic and muscular dystrophy), infection, trauma, connective tissue disease, strenuous exercise, drug overdose, drug reaction, seizures, ischemia, and electrolyte derangements [1]. Electrolyte abnormalities associated with rhabdomyolysis include hypokalemia, hypocalcemia, hypophosphatemia, hyponatremia, hypernatremia, of which hypokalemia 
Table 1. Results of the patient's immunological testing.

\begin{tabular}{|c|c|c|}
\hline & Result & Normal values \\
\hline Human immunodeficiency virus (HIV) antibody & Negative & Negative \\
\hline C3 & $113 \mathrm{mg} / \mathrm{dl}$ & $90-180 \mathrm{mg} / \mathrm{dl}$ \\
\hline $\mathrm{C} 4$ & $27 \mathrm{mg} / \mathrm{dl}$ & $10-40 \mathrm{mg} / \mathrm{dl}$ \\
\hline CH50 & $51 \mathrm{U} / \mathrm{ml}$ & $23-60 \mathrm{U} / \mathrm{ml}$ \\
\hline CD2 ( $\mathrm{T}$ cells) & $78 \%$ & $71 \%-81 \%$ \\
\hline CD3 ( $\mathrm{T}$ cells) & $76 \%$ & $60 \%-74 \%$ \\
\hline CD4 (T cells) & $44 \%$ & $37 \%-48 \%$ \\
\hline CD8 ( $\mathrm{T}$ cells) & $26 \%$ & $25 \%-31 \%$ \\
\hline 4:8 ratio ( $\mathrm{T}$ cells) & 1.67 & $1.05-2.61$ \\
\hline CD 56 NK cell & $2 \%$ & $3 \%-10 \%$ \\
\hline CD19 (B cell) & $21 \%$ & $2 \%-11 \%$ \\
\hline IgA & $17 \mathrm{mg} / \mathrm{gl}$ & $70-400 \mathrm{mg} / \mathrm{dl}$ \\
\hline IgG 1 & $260 \mathrm{mg} / \mathrm{dl}$ & 315 - $855 \mathrm{mg} / \mathrm{dl}$ \\
\hline IgG 2 & $16 \mathrm{mg} / \mathrm{dl}$ & $64-495 \mathrm{mg} / \mathrm{dl}$ \\
\hline IgG 3 & $14 \mathrm{mg} / \mathrm{dl}$ & $23-196 \mathrm{mg} / \mathrm{dl}$ \\
\hline IgG 4 & $<1 \mathrm{mg} / \mathrm{dl}$ & 11 - $157 \mathrm{mg} / \mathrm{dl}$ \\
\hline IgG total & $328 \mathrm{mg} / \mathrm{dl}$ & $842-2013$ mg/dl \\
\hline $\operatorname{Ig} M$ & $28 \mathrm{mg} / \mathrm{dl}$ & $40-230 \mathrm{mg} / \mathrm{dl}$ \\
\hline IgE & $4.5 \mathrm{mg} / \mathrm{dl}$ & 0 - $200 \mathrm{mg} / \mathrm{dl}$ \\
\hline
\end{tabular}

is the most common, accounting for $14 \%-28 \%$ of cases of rhabdomyolysis due to electrolyte abnormalities [2]. However, hypokalemia may go unrecognized as the cause of rhabdomyolysis due to the release of potassium from damaged muscle into the circulation [3]. Conversely, subclinical rhabdomyolysis may be missed; biochemical evidence of rhabdomyolysis was documented in 32\% of hypokalemic patients in one study [4]. As exemplified in our patient, hypokalemia can result secondary to potassium loss in the stool due to diarrhea. The chronic nature of our patient's complaints of diarrhea, stunted growth, and weight loss prompted an evaluation for celiac disease, as hypokalemic myopathy is a rarely reported complication of celiac disease [2] [5] [6]. Screening serology was not useful, as the patient was deficient for immunoglobulin A (IgA), which occurs in about 2\% of individuals with celiac disease [7]. Subsequent endoscopy documented normal duodenal histology, excluding celiac disease.

As the initial suspicion for celiac disease was excluded by upper endoscopy, colonoscopy was performed to assess for colonic causes of persistent diarrhea. Although the colon appeared grossly normal, biopsies showed a significant number of apoptotic cells in the colonic mucosa, extending from the transverse colon to the rectum. The finding of small numbers of apoptotic cells in normal colonic mucosa is expected as "physiological" apoptosis results in loss of senescent colonocytes without release of inflammatory cytokines. Apoptotic cells can also be seen as nuclear dust within the lamina propria of the colon, being more commonly found in patients with colitis (84\%) than patients with normal colons (11\%) [8]. Colitis due to Crohn's disease and ulcerative colitis is associated with an increased apoptotic rate, while lymphocytic colitis has apoptotic rates similar to that of normal colon [9]. Although apoptosis related to normal cell turnover does not alter epithelial barrier, apoptosis due to inflammation does lead to epithelial dysfunction. The proinflammatory cytokines tumor necrosis factor- $\alpha$ (TNF $\alpha$ ) and interleukin (IL)-13 increase the apoptotic rate and increase apoptotic conductivity, compared to physiologic apoptosis. The increased conductance leads to a loss of electrolytes and water into the intestinal lu- 
men resulting in diarrhea [9].

The differential diagnosis for apoptotic colitis includes GVHD, HIV infection, drug-induced colonopathy, and immunodeficiency syndromes. In our patient GVHD was excluded by history and HIV infection was excluded by serological testing. Medications associated with apoptotic colitis include proton-pump inhibitors, non-steroidal anti-inflammatory drugs, and the immunosuppressant mycophenolate mofetil [10] [11]. Apoptotic colitis accounts for $2 \%$ of drug-related colitides, often mimicking GVHD [11]. The patient described herein was receiving no medications prior to onset of symptoms, ruling out a drug-related process. Subsequent testing showed that the patient had common variable immunodeficiency (CVID) due to a defect in inducible costimulator (ICOS).

Clinical presentation of CVID is heterogenous, gastrointestinal manifestations include sprue-like syndrome, intestinal nodular lymphoid hyperplasia, colitis, small bowel lymphoma, gastric atrophy, and achlorhydria. Similarly, the histological findings of the gastrointestinal tract in CVID are highly variable; the findings may mimic inflammatory bowel disease, granulomatous inflammation, GVHD, lymphocytic colitis, collangenous colitis, and apoptotic colitis [12]. In a small study addressing gastrointestinal pathology in patients with CVID, significant apoptotis was found in the colons of $50 \%$ of the patients. Smaller percentage of patients had apoptosis in the stomach (33\%), small intestine (20\%), and esophagus (5\%) [12].

CVID is defined by a decrease in serum IgG and at least one other immunoglobulin isotype (usually IgA or IgM), functional defect in IgG response to immunizations, reduced numbers of memory B-cells, onset $>2$ year of age, and exclusion of other causes of hypogammaglobulinemia [13] [14]. CVID is the second most common primary immunodeficiency, having a prevalence rate of 1:25,000; specific IgA deficiency is the most common, having a prevalence rate of 1:600. The age of onset of CVID has two major peaks, childhood (5 to 10 years) and early adulthood (20 to 30 years) [14]-[17].

Most cases of CVID are sporadic, with only 10\% - 20\% having a positive family history [18]. CVID can arise from a number of different gene defects. Defects in TACI are inherited in an autosomal dominant fashion and account for less than $10 \%-15 \%$ of individuals with CVID. Autosomal recessive defects include CD19 deficiency, BAFF-R deficiency, and ICOS deficiency; each account for $<1 \%$ of individuals with CVID [19].

The ICOS belongs to the family of costimulatory $\mathrm{T}$ cell molecules, which also includes CD28 and cytotoxic T-lymphocyte antigen-4. ICOS is only expressed on activated T cells where it co-induces the secretion of cytokines (IL-4, IL-5, IL-6, GM-CSF, TNF- $\alpha$, and IFN- $\gamma$ ) and the superinduction of IL-10. IL-10 is a key cytokine for antibody production and germinal center B-cell survival [20]. Highest expression of ICOS is found within the $\mathrm{T}$ cell zones of secondary lymphoid organs and in the apical light zones of germinal centers. This expression pattern and the cytokines induced by ICOS point to an important role of ICOS:ICOS-ligand interaction in mediating T-B cell cooperation and promoting the terminal differentiation of B cells into memory cells and plasma cells [21] [22].

\section{Conclusion}

In conclusion, we present a young man who presented with hypokalemic-induced rhabdomyolysis resulting from potassium loss from chronic diarrhea. Investigation led to a diagnosis of apoptotic colitis, an uncommon cause of colitis with a limited differential diagnosis. The etiology of apoptotic colitis in this young man was CVID. Physicians should be aware of this rare association, and consider evaluation for immune deficiency when apoptotic colitis is identified at colonoscopy.

\section{References}

[1] Mannix, R., Tan, M.L., Wright, R. and Baskin, M. (2006) Acute Pediatric Rhabdomyolysis: Causes and Rates of Renal Failure. Pediatrics, 118, 2119-2125. http://dx.doi.org/10.1542/peds.2006-1352

[2] Barta, Z., Miltenyi, Z., Toth, L. and Illes, A. (2005) Hypokalemic Myopathy in a Patient with Gluten-Sensitive Enteropathy and Dermatitis Herpetiformis Duhring: A Case Report. World Journal of Gastroenterology, 11, 2039-2040.

[3] Vanholder, R., Sever, M.S., Erek, E., et al. (2000) Rhabdomyolysis. Journal of the American Society of Nephrology, 11, 1553-1561.

[4] Singhal, P.C., Abramovici, M., Venkatesan, J., et al. (1991) Hypokalemia and Rhabdomyolysis. Mineral and Electrolyte Metabolism, 17, 335-339.

[5] Ertekin, V., Selimoğlu, M.A., Tan, H. and Kiliçaslan, B. (2003) Rhabdomyolysis in Celiac Disease. Yonsei Medical Journal, 44, 328-330. 
[6] Williams, S.G., Davison, A.G. and Glynn, M.J. (1995) Hypokalaemic Rhabdomyolysis: An Unusual Presentation of Coeliac Disease. European Journal of Gastroenterology and Hepatology, 7, 183-184.

[7] Chow, M.A., Lebwohl, B., Reilly, N.R. and Green, P.H. (2012) Immunoglobulin: A Deficiency in Celiac Disease. Clinical Gastroenterology, 46, 850-854. http://dx.doi.org/10.1097/MCG.0b013e31824b2277

[8] Shichijo, K., Shin, T., Wen, C.Y., et al. (2007) Expression of Apoptotic Epithelial Cells in Biopsy Specimens of Patients with Colitis. Digestive Diseases and Science, 52, 2037-2043. http://dx.doi.org/10.1007/s10620-006-9263-5

[9] Schulzke, J.D., Bojarski, C., Zeissig, S., et al. (2006) Disrupted Barrier Function through Epithelial Cell Apoptosis. Annals of the New York Academy of Sciences, 1072, 288-299. http://dx.doi.org/10.1196/annals.1326.027

[10] Shepard, N.A. (2000) Muciphages and Other Mucosal Accumulations in the Colorectal Mucosa. Histopathology, 36, 559-562.

[11] Villanacci, V., Casella, G. and Bassotti, G. (2011) The Spectrum of Drug-Related Colitides: Important Entities, though Frequently Overlooked. Digestive and Liver Disease, 43, 523-528. http://dx.doi.org/10.1016/j.dld.2010.12.016

[12] Daniels, J.A., Lederman, H.M., Maitra, A. and Montgomery, E.A. (2007) Gastrointestinal Tract Pathology in Patients with Common Variable Immunodeficiency (CVID): A Clinicopathologic Study and Review. American Journal of Surgical Pathology, 31, 1800-1812. http://dx.doi.org/10.1097/PAS.0b013e3180cab60c

[13] Conley, M.E., Notarangelo, L.D. and Etzioni, A. (1999) Diagnostic Criteria for Primary Immunodeficiencies. Representing PAGID (Pan-American Group for Immunodeficiency) and ESID (European Society for Immunodeficiencies). Clinical Immunology, 93, 190-197. http://dx.doi.org/10.1006/clim.1999.4799

[14] Cunningham-Rundles, C. and Bodian, C. (1999) Common Variable Immunodeficiency: Clinical and Immunological Features of 248 Patients. Clinical Immunology, 92, 34-48. http://dx.doi.org/10.1006/clim.1999.4725

[15] Spickett, G.P., Farrant, J., North, M.E., et al. (1997) Common Variable Immunodeficiency: How Many Diseases? Immunology Today, 18, 325-328. http://dx.doi.org/10.1016/S0167-5699(97)01086-4

[16] Morimoto, Y. and Routes, J.M. (2008) Immunodeficiency Overview. Primary Care, 35, 159-173. http://dx.doi.org/10.1016/j.pop.2007.09.004

[17] Yarmohammadi, H., Estrella, L., Doucette, J., et al. (2006) Recognizing Primary Immune Deficiency in Clinical Practice. Clinical and Vaccine Immunology, 13, 329-332. http://dx.doi.org/10.1128/CVI.13.3.329-332.2006

[18] Kralovicova, J., Hammarstrom, L., Plebani, A., et al. (2003) Fine-Scale Mapping at IGAD1 and Genome-Wide Genetic Linkage Analysis Implicate HLA-DQ/DR as a Major Susceptibility Locus in Selective IgA Deficiency and Common Variable Immunodeficiency. Journal of Immunology, 170, 2765-2775. http://dx.doi.org/10.4049/jimmunol.170.5.2765

[19] Scharenberg, A.M., Hannibal, M.C., Torgerson, T., et al. (1993-2003) In: Pagon, R.A., Adam, M.P., Bird, T.D., Dolan, C.R., Fong, C.T. and Stephens, K., Eds., Common Variable Immune Deficiency Overview, GeneReviews ${ }^{\mathrm{TM}}$ [Internet]. University of Washington, Seattle.

[20] Hutloff, A., Dittrich, A.M., Beier, K.C., et al. (1999) ICOS Is an Inducible T-Cell Costimulator, Structurally and Functionally Related to CD28. Nature, 397, 263-266. http://dx.doi.org/10.1038/16717

[21] Beier, K.C., Hutloff, A., Dittrich, A.M.C., et al. (2000) Induction, Binding Specificity and Function of Human ICOS. European Journal of Immunology, 30, 3707-3717. http://dx.doi.org/10.1002/1521-4141(200012)30:12<3707::AID-IMMU3707>3.0.CO;2-Q

[22] Rousset, F., Garcia, E., Defrance, T., et al. (1992) Interleukin 10 Is a Potent Growth and Differentiation Factor for Activated Human B Lymphocytes. Proceedings of the National Academy of Science USA, 89, 1890-1893.

http://dx.doi.org/10.1073/pnas.89.5.1890

\section{Abbreviations}

BAFF-R: B-Cell Activating Factor Receptor

CVID: Common-Variable Immunodeficiency

GVHD: Graft-Versus-Host Disease

ICOS: Inducible T-Cell Costimulator

TACI: Transmembrane Activator, Calcium-Modulator, and Cycophilin Ligand Interactor 